\title{
Composition of Cereal Bars
}

\author{
Svetlana Aleksejeva ${ }^{1}$, Inese Siksna ${ }^{2}$ and Signe Rinkule ${ }^{1}$ \\ 1. Rīga Stradiņš University, 16 Dzirciema Street, Rīga LV-1007, Latvia \\ 2. BIOR Institute of Food Safety, Animal Health and Environment, 3 Lejupes Street, Rīga LV-1076, Latvia
}

\begin{abstract}
The aim of this study was to analyze ingredients of cereal bars - as indicated on the labels of these products, and to perform a factual analysis of nutritional values indicated therein. The analysis of the nutrients of cereal bars was performed at the laboratory of the Institute BIOR (BIOR Institute of Food Safety, Animal Health and Environment). Results showed that information about nutrients indicated on the labels mostly does not correspond to the actual values, however, they lie within the tolerance range and are lower than the actual determined value. Cereal bars are a source of fiber, but have high sugar content.
\end{abstract}

Key words: Cereal bar, nutritional value, label accuracy, fiber, sugar.

\section{Introduction}

A cereal bar is a bar-shaped food product, made by pressing cereals and usually dried fruit or berries, which are in most cases held together by glucose syrup. Consumers choose cereal bars as an alternative to the less-healthy snacks, a quick source of energy before a workout, or a substitute for a meal. In the 1990s, Americans used (and use to this day) cereal bars as a quick source of energy mostly in such sports as cycling, mountain climbing, and marathon running, but the consumer segment has grown much bigger since, and cereal bars are also widely used by casual consumers [1].

Global consumption of cereal bars rose $11 \%$ in 2007, and the market of cereal bars is estimated at around USD 4 billion. As a result, and to draw more consumers, cereal bars were becoming increasingly different, available with a great diversity of ingredients [2]. At the moment, there is no single international classification system for cereal bars - they do not belong to any particular group of food products. In some countries' food product databases, cereal bars fall into the same category as snacks, muesli, sweets, breakfast cereals, etc.

Corresponding author: Svetlana Aleksejeva, research field: nutrition.
Cereal bars are used for various purposes and in a variety of instances, therefore it is important for consumers to choose a product that suits their needs and physical stress the best. Many consumers use nutritional facts labels when choosing what product to buy, and usually consider nutritional values provided in a label to be very reliable source of information [3]. They make an informed choice based on what is stated in the labels. According to Regulation No. 1169/2011 of the European Parliament and the Council (2014, Article 9), food products that have to mandatory have nutrition declaration on packaging concerning the following: the presence of energy and nutrients in the product (carbohydrates, sugar, fat, saturates, protein and salt contents).

Nutritional facts labels on food products are considered a very reliable source of information [3]. However, several studies have raised question about the validity of data provided in the labels on various products marketed as snacks or sweets [4]. Imprecise labels concern not only snacks, but also food served in restaurants, energy-reduced products, and frozen food - some products contained on the average more than $245 \%$ of the declared energy values [5]. Imprecise labels have particular impact on those consumers who use nutritional facts labels as guidelines for weight control. By consuming cereal bars whose labels 
provide incorrect nutritional facts, consumers may unknowingly affect their weight, and not even know why. Therefore product labels must not be misleading to consumers.

\section{Materials and Methods}

\subsection{Materials: Sample Collection}

The criteria for identification of research sample group included shape (bar shape), size (small — meant to be held in one hand), packaging (individual sealed packaging), the label indicates one of the cereals in Latvian (pilngraudu, graudaugu, graudu (kukurūzas, rīsu, kviešu, miežu, sorgo, prosu, auzu, rudzu, tritikāles) or the original packaging or the label offer the information in the original language or the language of the country of origin (wholegrain, cereal, grain (corn, rice, wheat, barley, sorghum, millet, oats, rye, triticale), muesli, granola, flapjack.

Samples for the survey were collected at places where people buy food on a daily basis - retail chains, as well as places where people can buy food on the go -filling stations, convenience stores, cafes, which may have greater ranges of snacks. In addition, samples were also taken at ECO stores that are frequented by those who try to live healthy lifestyle.

A total of 40 different cereal bars were collected from 20 different retail outlets in Riga. 3 (three) samples had to be left out as their packaging did not indicate the product's energy value nor nutritional value, therefore the total number of samples in the group was 37 bars. Information about the bars was collated in a table, including the following: name, place it was bought, producer and country of origin, brand, flavor and coating, weight in grams, energy value in kilocalories 100 grams, fat, carbohydrates, sugar, protein, fiber amount in grams per 100 grams, price in euro per bar, and ingredients (listed on the label).

All samples in the given research were divided in two main groups, coated (17 bars) and uncoated (20 bars). The group of coated cereal bars was further divided according to the type of coating: chocolate (1st group) - eight bars and yogurt coating (2nd group) -nine bars. Cereal bars without coating belong to the 3rd group. As the research continued, permission to have 10 samples tested was received from the BIOR laboratory. Given that there are no data on what cereal bars are preferred by consumers, and the limited number of samples to be analyzed, samples representing each of the three groups were selected for research (Table 1).

\subsection{Methods}

The following standards were used for laboratory analysis of fat, protein, ash and moisture of samples:

- LVS EN ISO 11085 "Cereals, cereals-based products and animal feeding stuffs - Determination of crude fat and total fat content by the Randall extraction method (ISO 11085:2015)";

- LVS ISO 20483:2014 "Cereals and pulses-Determination of the nitrogen content and calculation of the crude protein content-Kjeldahl method (ISO 20483:2013)";

- GOST 5900-73 "Confectionery. Methods for determination of moisture and dry substances";

- GOST 5901-87 "Confectionery. Methods for determination of ash and metallomagnetic admixture content";

- Total Carbohydrate calculation was made by difference: $100 \%$ - (Protein (\%) + Fat (\%) + Moisture $(\%)+$ Ash (\%));

- Carbohydrate calculation was made by difference: Total Carbohydrate (\%) —Crude Fiber (\%);

- Nutritional values (kcal) were calculated values: Protein (kcal) + Carbohydrate (kcal) + Fat (kcal).

A comparison of nutritional values requires values expressed in both kilocalories and grams-the conversion factors, according to Regulation No. 1169/2011 of the European Parliament and the Council (2011, Annex 15) are the following (Table 2):

According to recommendations provided by the European Commission's Directorate-General for Health 
Table 1 Sample name, ID and group.

\begin{tabular}{lll}
\hline ID & Sample name & Group \\
\hline 1 & Wholebake "Flapjack" & 2nd \\
2 & Schwartauer Werke "Corny Big Cranberry" & $3 \mathrm{rd}$ \\
3 & Laima "Get Up! Cherry" & $3 \mathrm{rd}$ \\
4 & Nestle "Fitness strawberry" & $3 \mathrm{rd}$ \\
5 & Costa "Fruity Flapjack" & $3 \mathrm{rd}$ \\
6 & Rīgas Dzirnavnieks "Active\&Fit" & $2 \mathrm{nd}$ \\
7 & Eat Natural "Eat Natural" & $1 \mathrm{st}$ \\
8 & InGo "Musli Bar" & $3 \mathrm{rd}$ \\
9 & Schwartauer Werke "Corny Free Yoghurt" & $2 \mathrm{nd}$ \\
10 & Rīgas Dzirnavnieks "Crispy Friends" & $1 \mathrm{st}$ \\
\hline
\end{tabular}

Table 2 Conversion factors for calculating energy value.

\begin{tabular}{lll}
\hline No. & Nutrients & $\mathrm{kcal} / \mathrm{g}$ \\
\hline 1 & Fat & 9 \\
2 & Carbohydrates & 4 \\
3 & Fiber & 2 \\
4 & Proteins & 4 \\
\hline
\end{tabular}

Table 3 Tolerances, including measurement uncertainty.

\begin{tabular}{lll}
\hline \multicolumn{2}{l}{ Nutritional values } & Tolerances per $100 \mathrm{~g}$ \\
\hline \multirow{2}{*}{ Carbohydrates, } & $<10 \mathrm{~g}$ & $+/-2 \mathrm{~g}$ \\
proteins & $10-40 \mathrm{~g}$ & $+/-20 \%$ \\
& $>40 \mathrm{~g}$ & $+/-8 \mathrm{~g}$ \\
& $<10 \mathrm{~g}$ & $+/-1.5 \mathrm{~g}$ \\
Fat & $10-40 \mathrm{~g}$ & $+/-20 \%$ \\
& $>40 \mathrm{~g}$ & $+/-8 \mathrm{~g}$ \\
\hline
\end{tabular}

and Consumers, the actual energy values and composition of a product may differ from that indicated on the packaging due to natural differences and changes that may occur during the production process or storage. However, nutrient composition may not differ significantly from what is indicated on the label so as not to mislead consumers. Several tolerances apply to information provided in the label, including measurement uncertainty, as provided in Table 3 [6].

\section{Results and Analysis}

\subsection{Results}

\subsubsection{Proteins}

Protein values in four samples correspond to values indicated in the labels, and protein values in all these samples are within the tolerance range. The actual protein values range from $6 \mathrm{~g} / 100 \mathrm{~g}(24 \mathrm{kcal} / 100 \mathrm{~g})$ to $10 \mathrm{~g} / 100 \mathrm{~g} \mathrm{(40} \mathrm{kcal/100} \mathrm{g),} \mathrm{and} \mathrm{the} \mathrm{sources} \mathrm{of} \mathrm{proteins}$ include nuts, seeds, cereals and products thereof. Protein values for all samples are within the tolerance range stated in the labels.

\subsubsection{Fats}

Fat values for five samples correspond to the values indicated in the labels, and fat values for nine samples fall within the tolerance range. One sample (InGo "Muesli Bar with Cranberries") has fat value outside the tolerance range - it is $3 \mathrm{~g}$ ( $27 \mathrm{kcal})$ below the lower tolerance limit, and smaller by $7 \mathrm{~g}(63 \mathrm{kcal})$ than that indicated in the label. Fat value for the 7th sample (Eat Natural "Eat Natural") is close to the upper limit of the tolerance range. Furthermore, fat value in this product is higher by $5 \mathrm{~g}$ ( $45 \mathrm{kcal})$ than that indicated in the label. Actual fat values in the samples range from $8 \mathrm{~g} / 100(72 \mathrm{kcal} / 100 \mathrm{~g})$ to 30 $\mathrm{g} / 100 \mathrm{~g} \mathrm{(270} \mathrm{kcal} / 100 \mathrm{~g})$.

\subsubsection{Carbohydrates}

Carbohydrate value corresponds to value given in the label for one sample. For seven samples, carbohydrate values fall within the tolerance range, while carbohydrate values in two samples are beyond the tolerance range: carbohydrate values for the 8th sample (InGo "Muesli Bar with Cranberries) and 7th sample (Eat Natural "Eat Natural") are higher by $12 \mathrm{~g}$ (48 kcal). The actual carbohydrate values for the samples range from $53 \mathrm{~g} / 100(212 \mathrm{kcal} / 100 \mathrm{~g})$ to 71 $\mathrm{g} / 100 \mathrm{~g}(284 \mathrm{kcal} / 100 \mathrm{~g})$.

\subsubsection{Nutritional Value}

Analysis of the values calculated finds that the difference between the calculated values and those provided in the labels ranges from $32 \mathrm{kcal}(7.2 \%)$ (nutritional value for the 8th sample InGo "Muesli Bar with Cranberries" is lower than that indicated in the label) to $58 \mathrm{kcal}$ (17.1\%) (nutritional value for the 9th sample Schwartauer Werke "Corny Free Yogurt" is higher than that indicated in the label).

Given that each input in energy value calculations has individual tolerances, the absolute minimum and 
maximum energy values can be calculated. The absolute minimum energy value is the sum of the minimum tolerance values, in kilocalories, for proteins, fat and carbohydrates. The absolute maximum energy value is the sum of upper tolerance values, in kilocalories, for proteins, fat and carbohydrates. An analysis of the calculated energy values and the absolute minimum and maximum values finds that energy values in two products are higher than the absolute maximum: energy value of the 6th sample (Rīgas Dzirnavnieks "Active \& Fit") exceeds the absolute maximum by $4 \mathrm{kcal}$, and energy value of the 7th sample (Eat Natural "Eat Natural")-by 29 kcal.

The actual energy values for the samples range from $381 \mathrm{kcal} / 100 \mathrm{~g}$ to $501 \mathrm{kcal} / 100 \mathrm{~g}$.

\subsubsection{Sugar}

Collated data on sugar content show that no sugar content is indicated for one sample (1st sample-Wholebake "Flapjack"). For the other nine, sugar content ranges from $23 \mathrm{~g} / 100 \mathrm{~g}$ (Nestle "Fitness Strawberry") to $42 \mathrm{~g} / 100 \mathrm{~g}$ (Laima "Get Up! Cherry").

\subsubsection{Fiber}

Analysis of information indicated in the labels finds that half (five) of the samples offered no data on the amount of fiber. According to the European Parliament and the Council Regulation (2006, No. 1924/2006), if $100 \mathrm{~g}$ of a product contain at least $3 \mathrm{~g}$ of fiber, the product is considered a source of fiber, and if $100 \mathrm{~g}$ of a product contain at least $6 \mathrm{~g}$ of fiber, it is considered to be rich in fiber. Based on the date provided in the labels, three samples may be considered source of fiber, and two cereal bars had high fiber content- the amount of fiber is shown in the chart.

\subsection{Analysis}

Values calculated for the samples show that just one sample-Schwartauer Werke "Corny Big Cranberry"- had all the element values (protein, fat and carbohydrates) meet the values indicated in the label by $100 \%$. Most samples - four-had the value of one element exceeded as compared to that provided in the label. In three samples, two elements' values exceeded the values given in the label, and in three samples, all three elements' values were higher than those given in the labels (Fig. 1).

In the total number of samples, analysis found that four had the same protein content, three the same fat content, and one the same level of carbohydrate content as indicated in their labels (Fig. 2).

In most samples, values given in the labels are lower than those found in laboratory tests-Fig. 2.

Fat value found in the 8th sample (InGo "Muesli Bar with Cranberries") is lower than that indicated in the label, and beyond the tolerance range. The deviation from the value given in the label may be due to the product containing peanuts and peanut butter.

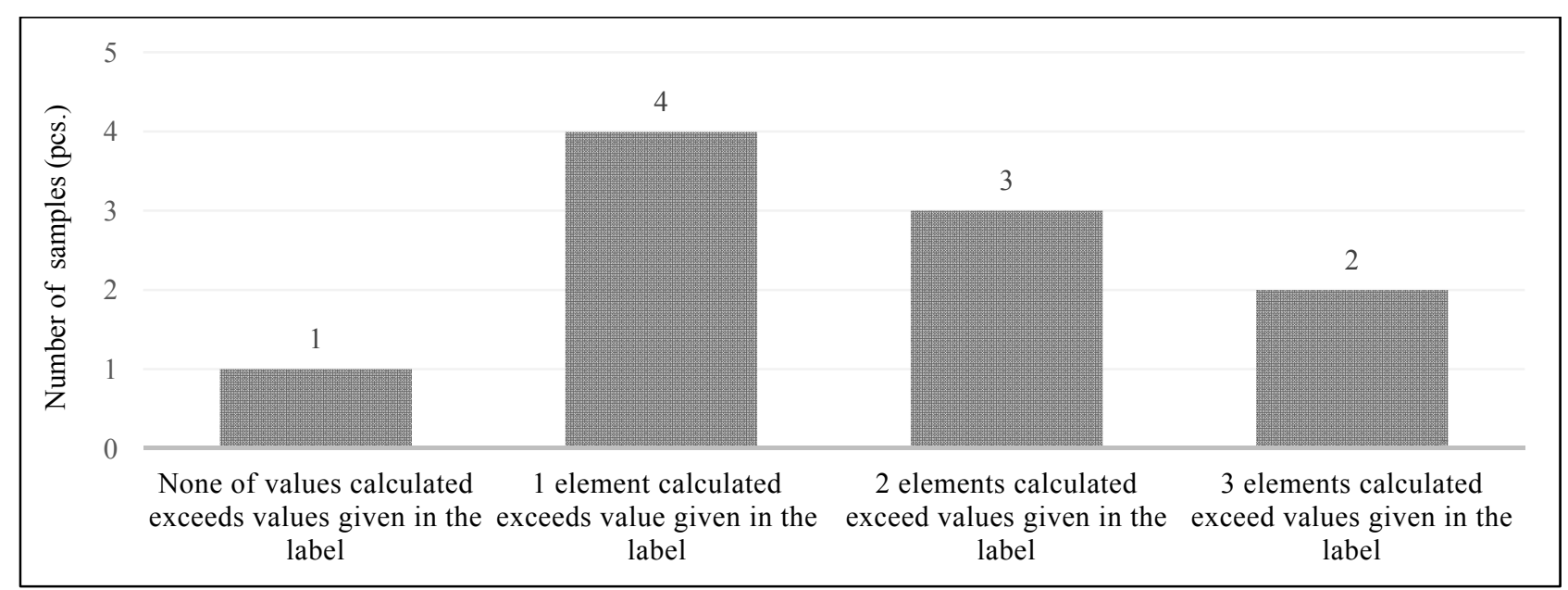

Fig. 1 Number of products with protein, carbohydrate and fat levels higher than values given in the labels. 


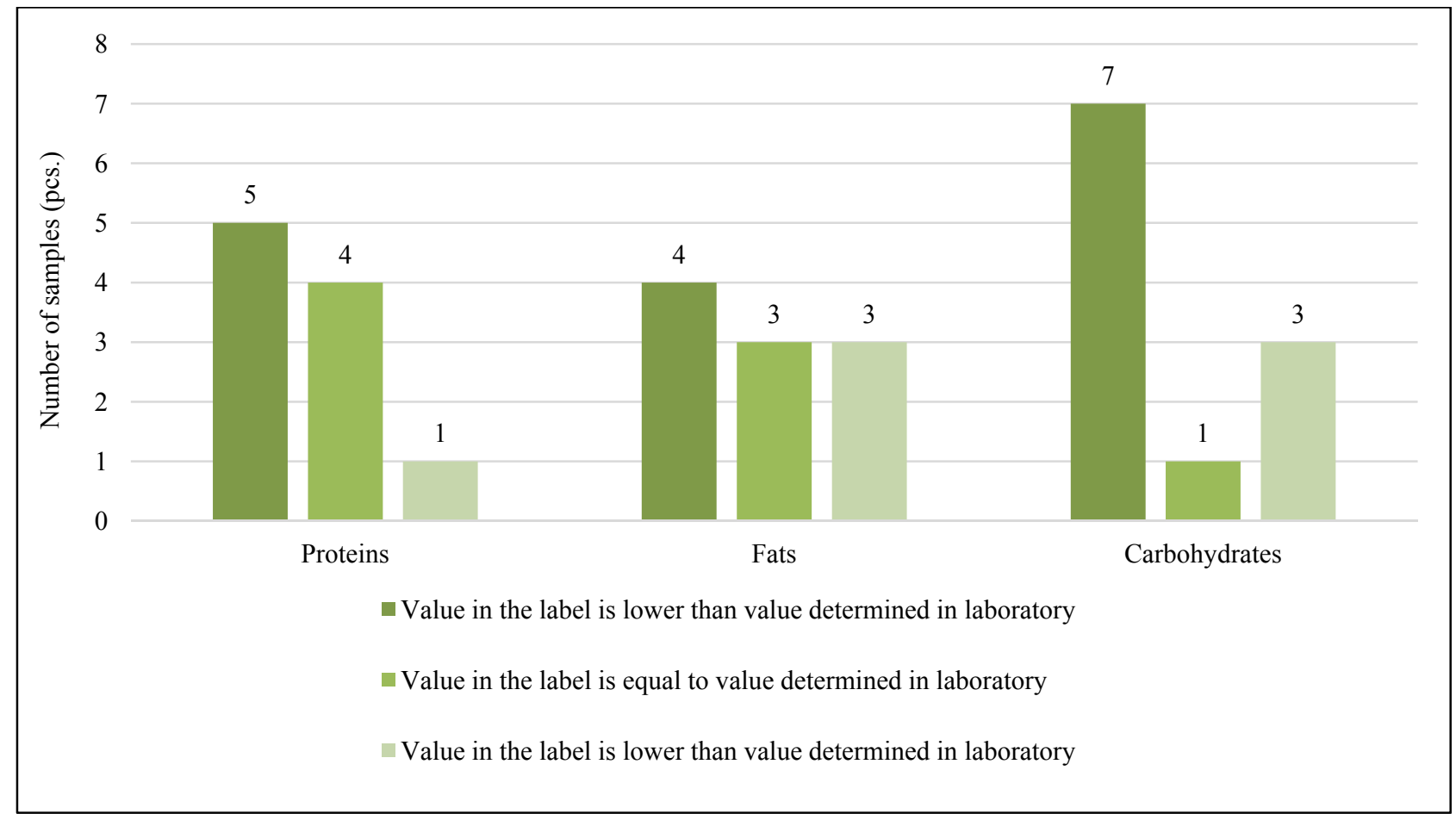

Fig. 2 Product labels with values below or over the actual values found via laboratory tests.

Taking into consideration that fat is a nutrient that consumers usually want to consume less, the producer of the bar should revise the fat values given in the label and correct them. In this particular case, consumers who try to decrease their fat intake may find the product rather attractive. In choosing cereal bars, consumers should pay attention to the ingredients and keep in mind that nut content may have an impact on the actual nutritional value and level of nutrients in the bar.

Carbohydrate values found in the 7th sample (Eat Natural "Eat Natural") and 8th sample (InGo "Muesli Bar with Cranberries") lie outside the tolerance range and are higher than indicated in the labels. Taking into account the trend to reduce carbohydrate intake, that is a substantial deviation from the value indicated in the labels. Therefore, data given in the labels may mislead consumers about the actual carbohydrate content in these products. The producers should be asked to explain the reasons for the deviation from tolerances.

Specific formulas are used to calculate energy values; therefore, no tolerance ranges apply. In four samples, the energy value is lower than that indicated in the labels, and in six samples, the actual energy value is higher. The biggest difference was found in the 9th sample (Schwartauer Werke "Corny Free Yogurt") - the value given in the label is by $58 \mathrm{kcal}$ lower than the calculated value. The situation is opposite in the 8th sample (InGo "Muesli Bar with Cranberries")- the value given in the label is by 32 kcal higher than the value calculated.

According to the European Commission's recommendations on tolerances for nutritional values indicated in labels, if a value calculated lies outside the tolerance range, the following aspects should, for example, be taken into account in this consideration:

(a) the nutrient in question;

(b) the extent of the deviation;

(c) the nature of the deviation (overestimation or underestimation) in relation to the nutrient concerned;

(d) natural high variation of the nutrient, including seasonality;

(e) particular high degradation rates of nutrients in some food matrices;

(f) particular high analytical variability of nutrients in a specific food matrix; 
(g) particular low homogeneity of a product leading to particular high variation of nutrient content in a product that is not offset by the sampling procedure;

(h) compliance of the majority of samples from the lot with the tolerance range, if such data are available;

(i) validity of the manufacturer's process for establishing the declared nutrient value;

(j) how the self-monitoring of the company functions in general;

(k) previous problems or previous sanctions against the company [6].

Following evaluation of the aspects above, the need to correct information provided in the label has to be considered as incorrect information in labels misleads consumers and affects the number of kilocalories consumed, which may influence a given person's weight or athletes' performance.

Analysis of information provided in the labels found that the samples have very high sugar contents. According to WHO recommendations, sugar should daily intake of free sugars has to be less than $10 \%$ of a person's total energy intake. In one sample (Laima "Get Up! Cherry"), sugar content is $84 \%$ of the recommended daily intake or, according to harsher recommendations limiting daily sugar intake to 5\%-168\% of the recommended daily intake. The high sugar content in Laima's "Get Up! Cherry" bar is due to the ingredients indicated in the label: honey, raisins, glucose syrup, sweetened condensed milk, sucrose, dextrose. The lowest sugar content was found in the 4th sample (Nestle "Fitness Strawberry") — 46\% of the recommended daily intake (less than $10 \%$ of a person's total energy intake), or 92 percent of the recommended daily intake which limits person's total energy intake to $5 \%$. For persons who do not exercise and consume such cereal bars, observing the WHO recommendations is impossible. Persons who exercise should take into consideration the high sugar content when planning their meals, while persons who do not exercise should limit consumption of cereal bars.

Cereal products are considered a good source of fiber. However, half of labels on the samples offer no information about fiber content. This has an impact on consumers who pay attention to product labels. Still, the samples that do offer information about fiber content may be recommended to consumers because, according to the European Parliament and the Council's Regulation (2006, No. 1924/2006), the following bars may be classified as a source of fiber: Schwartauer Werke "Corny Big Cranberry", Nestle "Fitness Strawberry", Schwartauer Werke "Corny Free Yogurt"; and the following bars as products rich in fiber: Wholebake "Flapjack", Rīgas Dzirnavnieks "Active\&Fit". Whole bake "Flapjack" bar has the highest fiber content $(20 \mathrm{~g} / 100 \mathrm{~g})$, derived from sources such as oatmeal (34\%) and dried berries (3\%). To consumers, $100 \mathrm{~g}$ of the product ensures $57 \%$ of the recommended daily fiber intake. Consuming a lot of fiber by eating cereals twice a day over the course of 12 (twelve) weeks will help overweight or obese people shrink their waist and achieve low-density lipoprotein cholesterol [7]. The meta-analysis found that more frequent consumption of whole grains is strongly associated with reduced risk of cardiovascular diseases [8]. According to recommendations issued by the Latvian Ministry of Health, the optimal daily amount of fiber (ballast substances) is 30-35 $\mathrm{g}$ [9].

A comparison of the products' energy value based on coating did not find that cereal bars without coating have lower energy values.

Energy values of the samples differ significantly. For example, the difference between energy values of two bars analyzed amounted to $120 \mathrm{kcal}$. Actual fat values for the cereal bars analyzed also differ greatly, by up to $198 \mathrm{kcal}$. Likewise, actual carbohydrate values also differ, and the difference is up to $72 \mathrm{kcal}$. Sugar content in different bars differs drastically, up to $19 \mathrm{~g} / 100 \mathrm{~g}$, which equals approximately four teaspoons of sugar. The amount of fiber differs by up to $14.6 \mathrm{~g}$, which makes up approximately half of the recommended daily fiber intake. 


\section{Conclusions}

Information about nutritional value and nutrients indicated on the labels mostly does not correspond to the actual values, however, they lie within the tolerance range and are lower than the actual determined values. Erroneous labels are especially detrimental to those consumers who use nutrition labels as guidelines for weight control.

Cereal bars are a source of fiber, but at the same time cereal bars have high sugar content.

Cereal bars do not have the same nutrients and nutritional values. Nutritional values and nutrients may vary greatly, and that is determined by the ingredients of the bar. The fact that a bar is named a "cereal bar" does not necessarily mean that this is a healthy snack, therefore consumers should pay attention to the ingredients, nutritional facts given in the nutritional facts label, and bear in mind that values indicated in the label have certain tolerance ranges and the data provided may lie outside them.

\section{References}

[1] Palazzolo, G. 2003. "Cereal Bars: They're Not Just for Breakfast Anymore." Cereal Foods World 48 (2): 70. Accessed March 04, 2016. http://search.proquest.com/ docview/230350166? accountid=32994.

[2] Sharma, C., Kaur, A., Aggarwal, P., and Singh, B. 2014. "Cereal Bars-A Healthful Choice a Review." Carpathian Journal of Food Science \& Technology 6 (2): 29-36.

[3] Campos, S., Doxey, J., and Hammond, D. 2014.
"Nutrition Labels on Pre-packaged Foods: A Systematic Review." Public Health Nutrition 14 (8): 1496-506. doi: 10.1017/S1368980010003290.

[4] Jumpertz, R., Venti, C. A., Le, D. S., Michaels, J., Parrington, S., Krakoff, J., and Votruba, S. 2013. "Food Label Accuracy of Common Snack Foods." Obesity (Silver Spring, Md.). doi: 10.1002/oby.20185.

[5] Urban, L. E., Dallal, G. E., Robinson, L. M., Ausman, L. M., Saltzman, E., and Roberts, S. B. 2010. "The Accuracy of Stated Energy Contents of Reduced-Energy, Commercially Prepared Foods." Journal of the American Dietetic Association $110 \quad$ (1): 116-23. http://doi.org/10.1016/j.jada.2009.10.003.

[6] European Commission Health and Consumers Directorate-General. 2012. "Guidance Document for Competent Authorities for the Control of Compliance with EU Legislation." Accessed April 01, 2016. https://ec.europa.eu/food/sites/food/files/safety/docs/label ling_nutrition-vitamins_minerals-guidance_tolerances_12 12 en.pdf.

[7] Maki, K., Beiseigel, J., Jonnalagadda, S., Gugger, C., Reeves, M., Farmer, M., Kaden, V., and Rains, T. 2010. "Whole Grain Ready-to-Eat Oat Cereal, as Part of a Dietary Program for Weight Loss, Reduces Low-density Lipoprotein Cholesterol in Overweight and Obese Adults More than a Dietary Program Including Low Fiber Control Foods." Journal of American Dietetic Association. doi: http://dx.doi.org/10.1016/j.jada.2009.10.037.

[8] Tang, G., Wang, D., Long, J. Yang, F. And Si, L. 2015. "Meta-Analysis of the Association between Whole Grain Intake and Coronary Heart Disease Risk." The American Journal of Cardiology. doi: http://dx.doi.org/10.1016/ j.amjcard.2014.12.015.

[9] Ministry of Health of the Republic of Latvia. Healthy Eating Recommendations for Adults. Accessed April 06, 2016. http://www.vm.gov.lv/lv/tava_veseliba/veseligs_uzturs/. 